Published in final edited form as:

Adv Drug Deliv Rev. 2013 January ; 65(1): 89-92. doi:10.1016/j.addr.2012.08.017.

\title{
Perspectives on the Interface of Drug Delivery and Tissue Engineering
}

\author{
Adam K. Ekenseair, F. Kurtis Kasper, and Antonios G. Mikos ${ }^{*}$ \\ Department of Bioengineering, Rice University, Houston, TX, 77030, USA
}

\begin{abstract}
Controlled drug delivery of bioactive molecules continues to be an essential component of engineering strategies for tissue defect repair. This article surveys the current challenges associated with trying to regenerate complex tissues utilizing drug delivery and gives perspectives on the development of translational tissue engineering therapies which promote spatiotemporal cell-signaling cascades to maximize the rate and quality of repair.
\end{abstract}

\section{Keywords \\ Scaffolds; Spatiotemporal Control; Extracellular Matrix; Tissue Regeneration; Translational Medicine}

\section{Introduction}

\begin{abstract}
Motivated primarily by a desire to improve our general quality of life, tissue engineers have sought for two decades to provide materials-based therapeutic solutions to enhance the rate and quality of tissue defect repair or regeneration. The prevailing paradigm combines the development of appropriate scaffolding materials with the co-delivery of seeded or encapsulated cells and signaling molecules such as peptides and proteins [1]. Within tissue engineering, nearly all applications of drug delivery involve the localized release of molecules of varying sizes and/or co-delivery of entire cells. Delivery schemes have ranged from simple matrix-embedding and encapsulation of drug-loaded microparticles to controlled and stimuli-responsive drug release to immobilization and covalent attachment of drugs to the scaffolds. We first briefly discuss drug delivery applications within each of five current primary challenges in tissue defect repair before turning to our perspective on where the field of tissue engineering research is generally headed.
\end{abstract}

The most studied application of drug delivery in tissue engineering has long been concerning efforts to induce cells, either recruited from the surrounding host tissue or codelivered within the scaffold to the defect site, to differentiate down the desired lineage. General and recent reviews on the methods and efficacy of tissue engineering are available for specific topical areas, including bone [2], cartilage [3], neural [4], cardiovascular [5], and general soft tissue regeneration [6].

\footnotetext{
(C) 2012 Elsevier B.V. All rights reserved.

“Corresponding author (A. G. Mikos): mikos@ rice.edu; Phone: 1 (713) 348-5355; Fax: 1 (713) 348-4244.
}

Publisher's Disclaimer: This is a PDF file of an unedited manuscript that has been accepted for publication. As a service to our customers we are providing this early version of the manuscript. The manuscript will undergo copyediting, typesetting, and review of the resulting proof before it is published in its final citable form. Please note that during the production process errors may be discovered which could affect the content, and all legal disclaimers that apply to the journal pertain. 
An emerging application of drug delivery concerns the modulation of the immune and inflammatory response to the implanted scaffold. While it has long been obvious that prolonged inflammation and aggressive foreign body responses due to implanted tissue engineering constructs is extremely detrimental to the successful regeneration and integration of new tissue, only recently has the field come to an understanding that early inflammatory processes within the first week of wound healing can be quite beneficial to the ultimate quality and rate of tissue repair [7]. Current efforts seek to modulate and harness the inflammatory process to enhance the rate of tissue regeneration in bone defects using controlled drug delivery [8].

When engineering regeneration strategies for vascularized tissues, the promotion of appropriate angiogenesis must also be considered; as generation of a local blood vessel network that is connected to the host supply is critical for sustained nutrient delivery and tissue functionality. Recent investigations have shown that angiogenesis can be significantly impacted by the mechanical properties of the implant as well as external mechanical stimuli [9]. While these methods likely stimulate local cell populations to generate angiogenic signals, more common approaches involve the localized controlled delivery of such angiogenic factors [10]. One promising avenue of current research involves the creation of three-dimensional perfusable vascular networks, around which a wide array of implantable tissue engineering constructs can be created [11].

While successful angiogenesis in tissue engineering constructs for vascularized tissues such as bone can have the added benefit of promoting integration with the surrounding environment, the complete and functional integration of implants with the native tissue remains a major challenge in avascular and soft connective applications such as cartilage and neural tissues. The current clinical approach is generally to promote integration with sutures or tissue adhesives, such as fibrin glue; however such approaches often display poor biocompatibility and bonding strength, particularly in cartilage applications. Currently evolving approaches to promoting tissue integration include the delivery of peptides and proteins, use of tissue-adhesive interfacial layers, and the development of adhesive structural architectures [12].

Finally, as the field moves toward clinical translation of tissue engineering therapies, the prevention and potential complicating effects of wound infection must be considered. For example, in bone tissue regeneration applications, the challenges associated with infections include decreased blood flow, reduced nutrient delivery, and the formation of necrotic tissues and/or pus [13]. While systemic delivery of antibiotics to treat infections can have a positive impact, there is a need for enhanced localized controlled delivery strategies within a tissue engineering construct to treat and/or prevent infection without negatively impacting the regeneration of new tissue $[14,15]$. In addition, many tissue engineering applications may require still more advanced drug delivery strategies to combat the formation of antibiotic-resistant biofilms [16].

\section{Spatiotemporal Control}

While each of these complexities have been addressed with varying degrees of success individually, the grand challenge in tissue engineering research going forward is creating therapies capable of addressing each of them in an appropriately controlled manner. A complication in general and in drug delivery strategies in particular is the potential for drug interactions and cross effects. For instance, while preventing infection and prolonged inflammation is critical for translation to wound healing applications, delivery of antibiotics and anti-inflammatory agents can have negative impacts on other regenerative processes, such as reducing the efficacy of osteogenesis in bone tissue repair [17]. Furthermore, a 
particular drug can have both positive and negative effects on tissue regeneration, depending on the stage of cellular differentiation down a particular lineage. Thus, not only must the drug cocktails to be delivered in a tissue engineering therapy be carefully selected, but a time-dependent drug delivery cascade sequence must be engineered. Early time prevention of wound infection, promotion of beneficial inflammatory processes, and induction of angiogenesis must be followed by longer-term cell proliferation, differentiation, and production of tissue-specific extracellular matrix (ECM). While this can be accomplished to a degree by use of composite scaffolding materials with drugs loaded into varied microparticles for passive release at differing rates, more effective strategies may involve tissue-specific, stimuli-responsive drug delivery.

In addition to temporal control, spatial control of drug delivery will be essential in many cases. In particular, the regeneration of articular cartilage is a major challenge due to the gradient nature of this highly avascular tissue [18]. The majority of cartilage regeneration strategies thus far have led to production of inferior fibrilar cartilage, which lacks the highly organized gradient structure of articular cartilage. Creating concentration gradients of delivered growth factors is one promising strategy to improve functional tissue repair and can potentially be accomplished through gradient incorporation of drug-releasing microparticles or reservoir delivery within multi-layered constructs. Beyond regeneration of simple tissue defects, the realities of clinical applications will necessitate tissue engineering strategies to regenerate complex and inhomogeneous defects [1]. Spatially compartmentalized and/or gradient drug delivery will be essential in successful therapies for such defects. For instance, bilayered scaffolds with compartmentalized drug delivery are being investigated for regeneration of osteochondral defects, where both bone and cartilage must be regenerated in their respective domains for functional repair [19]. Furthermore, spatially-controlled drug release will be an important tool to minimize the quantities of drugs to be used and delivered, both to mitigate potential effects in surrounding tissues and to reduce overall cost.

\section{Translation is Key}

While there are a multitude of essential and interesting research questions still to be answered in the use of complex drug delivery strategies for specific tissue regeneration applications, in particular the establishment of appropriate and effective spatiotemporal drug release cascades, researchers must also keep an eye towards the potential translation of such therapies to clinical use. With the emergence of FDA-approved and commercially successful tissue engineering therapies, the field has begun to move beyond initial scientific discovery. However, the more complex these therapies are made, particularly concerning the number and quantity of drugs to be delivered, the more challenging translation will become. Several recent reviews highlight the regulatory pathways available for and the challenges associated with translation of orthopedic [20-22] and heart valve [23] tissue engineering products.

In addition, the likelihood of patient-to-patient variability needs to be considered in an effort to design robust tissue engineering strategies that can either be easily tuned at the clinical stage as needed or are capable of adapting or overcoming variability in the surrounding tissue environment. Whether this will be most successfully accomplished with more simple or more complex strategies remains to be seen. For example, we have already discussed the importance of the inflammatory immune response in the healing process of tissue defects, however what happens if the patient is immune suppressed or has a hyperactive immune system due to any number of complications, most notably autoimmune and inflammatory diseases? Will the same therapy still work or can it be easily modulated at the clinical stage to suit the needs of a particular patient? While general therapeutic strategy development 
must initially target ideal conditions for a typical patient, the ultimate robustness and/or tunability of the tissue engineering strategy in a clinical setting is something to consider.

A current widely-pursued approach to increasing the regenerative efficacy of therapies is to co-deliver cells in the scaffolding material. With either the release of appropriate growth factors or the presence of appropriate cell-signaling capability within the scaffold, the cells can act as local drug depots potentially capable of controlling over time the appropriate signaling cascades. New techniques which label cells to allow for long-term in situ monitoring of cell fate, including use of quantum dots [24] and metallic contrast agents [25, 26] which can be loaded into cells in vitro, are enabling a new wave of more informative investigations into the efficacy of cellular delivery in tissue engineering, with high potential impact particularly in neural tissue regeneration strategies [25]. One especially promising approach utilizes gold nanotracers to label MSCs without altering cell function for subsequent visualization utilizing ultrasound-guided photoacoustic imaging [26, 27].

While significant ongoing research is evaluating the effects of the type of cells delivered and their degree of pre-differentiation on tissue regeneration, likely the most effective strategy will ultimately look similar to what happens in normal tissue repair. Specifically, the presence of both stem cells and differentiated cells from surrounding tissues enhances and controls the tissue regeneration process through modulation of the immune response and signaling cross-talk. For instance, delivery of co-cultures of mesenchymal stem cells and chondrocytes is showing promise for improved regeneration of cartilage or enhanced deposition of appropriate ECM on prefabricated scaffolds [28]. However, from a translation and commercialization perspective, the use of controlled drug delivery in lieu of cells has significant advantages in terms of sterilization, packaging, and often reduced regulatory hurdles.

One promising direction the field is heading involves incorporating cell-signaling capabilities into the scaffolding material in order to both reduce the variety and quantity of drug delivery required and potentially eliminate the need for co-delivery of cells. By recreating the cell niche, or the surrounding extracellular matrix composition, in the scaffold initially, differentiation of cells recruited from the native tissue can often be modulated without the co-delivery of growth factors. In addition, it might be possible to further modulate the spatial response of cells by varying the ECM or immobilized signal compositions present in the scaffold. Temporal control of tissue regeneration might also be accomplished through a degradation-dependent response. For instance, if immobilized growth factors are eventually released through degradation and allowed to diffuse away, the differing early and late time tissue repair processes could be facilitated. Current strategies for generating such complex scaffolds have been recently reviewed [29] and include using free form or inkjet bioprinting or layer-by-layer scaffold assembly to impart threedimensional spatial control [30,31] and the use of static and perfusion flow bioreactors for generation of ECM [32,33]. Especially challenging will be ongoing efforts to produce minimally invasive, injectable in situ-forming alternatives to preformed scaffolds [34-36].

\section{Concluding Remarks}

Clearly, there is still a monumental amount of research to be done in the field, both in terms of answering basic biological questions as to how different cells and signals interact to promote tissue repair and how best to recreate this process in a tissue engineering scaffold to create effective yet translatable therapies. The successful integration of spatiotemporallycontrolled drug delivery strategies will continue to be an essential element of the tissue engineering paradigm within this effort. While it is likely that in the end a number of effective options for the repair of a specific tissue type will be developed, the simpler and 
more robust therapies hold the most promise for translation. Presently, the most effective approaches seem to be those that include delivery of multiple types of drugs and/or cells to the defect within the scaffolding material; however these are also the systems with the highest regulatory hurdles to overcome in translation to the clinic. The emerging paradigm shift of designing advanced tissue engineering scaffolds which leverage delivery of cellgenerated ECM and immobilized signaling moieties, utilize co-delivery of cells as drugproducing depots, and incorporate space- and time-dependent functionality may facilitate the development of more translatable therapies.

\section{Acknowledgments}

The authors acknowledge support from the National Institutes of Health (R01 AR048756, R01 AR057083, and R01 DE017441), as well as from the Armed Forces Institute of Regenerative Medicine (W81XWH-08-2-0032).

\section{References}

1. Mikos AG, Herring SW, Ochareon P, Elisseeff J, Lu HH, Kandel R, Schoen FJ, Toner M, Mooney D, Atala A, Van Dyke ME, Kaplan D, Vunjak-Novakovic G. Engineering complex tissues. Tissue Eng. 2006; 12:3307-3339. [PubMed: 17518671]

2. Vo TN, Kasper FK, Mikos AG. Strategies for controlled delivery of growth factors and cells for bone regeneration. Adv Drug Delivery Rev. 2012; 64:1292-1309.

3. Spiller KL, Maher SA, Lowman AM. Hydrogels for the repair of articular cartilage defects. Tissue Eng, Part B. 2011; 17:281-299.

4. Jiang X, Lim SH, Mao HQ, Chew SY. Current applications and future perspectives of artificial nerve conduits. Exp Neurol. 2010; 223:86-101. [PubMed: 19769967]

5. Vunjak-Novakovic G, Tandon N, Godier A, Maidhof R, Marsano A, Martens TP, Radisic M. Challenges in cardiac tissue engineering. Tissue Eng, Part B. 2010; 16:169-187.

6. Ladewig K. Drug delivery in soft tissue engineering. Expert Opin Drug Delivery. 2011; 8:11751188.

7. Mountziaris PM, Mikos AG. Modulation of the inflammatory response for enhanced bone tissue regeneration. Tissue Eng, Part B. 2008; 14:179-186.

8. Mountziaris PM, Spicer PP, Kasper FK, Mikos AG. Harnessing and modulating inflammation in strategies for bone regeneration. Tissue Eng, Part B. 2011; 17:393-402.

9. Boerckel JD, Uhrig BA, Willett NJ, Huebsch N, Guldberg RE. Mechanical regulation of vascular growth and tissue regeneration in vivo. Proc Natl Acad Sci U S A. 2011; 108:E674-E680. [PubMed: 21876139]

10. Naderi H, Matin MM, Bahrami AR. Review paper: critical issues in tissue engineering: biomaterials, cell sources, angiogenesis, and drug delivery systems. J Biomater Appl. 2011; 26:383-417. [PubMed: 21926148]

11. Miller JS, Stevens KR, Yang MT, Baker BM, Nguyen DH, Cohen DM, Toro E, Chen AA, Galie PA, Yu X, Chaturvedi R, Bhatia SN, Chen CS. Rapid casting of patterned vascular networks for perfusable engineered three-dimensional tissues. Nat Mater. 2012; 11:768-774. [PubMed: 22751181]

12. Moroni L, Elisseeff JH. Biomaterials engineered for integration. Mater Today. 2008; 11:44-51.

13. Nair MB, Kretlow JD, Mikos AG, Kasper FK. Infection and tissue engineering in segmental bone defects - a mini review. Curr Opin Biotechnol. 2011; 22:721-725. [PubMed: 21354782]

14. Shi M, Kretlow JD, Spicer PP, Tabata Y, Demian N, Wong ME, Kasper FK, Mikos AG. Antibiotic-releasing porous polymethylmethacrylate/gelatin/antibiotic constructs for craniofacial tissue engineering. J Controlled Release. 2011; 152:196-205.

15. Spicer PP, Kretlow JD, Henslee AM, Shi M, Young S, Demian N, Jansen JA, Wong ME, Mikos AG, Kasper FK. In situ formation of porous space maintainers in a composite tissue defect. J Biomed Mater Res, Part A. 2012; 100A:827-833.

16. Flemming HC, Wingender J. The biofilm matrix. Nat Rev Microbiol. 2010; 8:623-633. [PubMed: 20676145] 
17. Rathbone CR, Cross JD, Brown KV, Murray CK, Wenke JC. Effect of various concentrations of antibiotics on osteogenic cell viability and activity. J Orth Res. 2011; 29:1070-1074.

18. Temenoff JS, Mikos AG. Review: tissue engineering for regeneration of articular cartilage. Biomaterials. 2000; 21:431-440. [PubMed: 10674807]

19. Holland TA, Bodde EWH, Baggett LS, Tabata Y, Mikos AG, Jansen JA. Osteochondral repair in the rabbit model utilizing bilayered, degradable oligo(poly(ethylene glycol) fumarate) hydrogel scaffolds. J Biomed Mater Res, Part A. 2005; 75A:156-167.

20. Evans $\mathrm{CH}$. Barriers to the clinical translation of orthopedic tissue engineering. Tissue Eng, Part B. 2011; 17:437-441.

21. Ratcliffe A. Difficulties in the translation of functionalized biomaterials into regenerative medicine clinical products. Biomaterials. 2011; 32:4215-4217. [PubMed: 21515170]

22. Ratcliffe A. The translation of product concept to bone products: a partnership of therapeutic effectiveness and commercialization. Tissue Eng, Part B. 2011; 17:443-447.

23. Mendelson K, Schoen FJ. Heart valve tissue engineering: concepts, approaches, progress, and challenges. Ann Biomed Eng. 2006; 34:1799-1819. [PubMed: 17053986]

24. Shah LS, Clark PA, Moioli EK, Stroscio MA, Mao JJ. Labeling of mesenchymal stem cells by bioconjugated quantum dots. Nano Lett. 2007; 7:3071-3079. [PubMed: 17887799]

25. Bible E, Dell'Acqua F, Solanky B, Balducci A, Crapo PM, Badylak SF, Ahrens ET, Modo M. Non-invasive imaging of transplanted human neural stem cells and ECM scaffold remodeling in the stroke-damaged rat brain by F-19- and diffusion-MRI. Biomaterials. 2012; 33:2858-2871. [PubMed: 22244696]

26. Ricles LM, Nam SY, Sokolov K, Emelianov SY, Suggs LJ. Function of mesenchymal stem cells following loading of gold nanotracers. Int J Nanomed. 2011; 6:407-416.

27. Nam SY, Ricles LM, Suggs LJ, Emelianov SY. In vivo ultrasound and photoacoustic monitoring of mesenchymal stem cells labeled with gold nanotracers. PLoS One. 2012; 7

28. Meretoja VV, Dahlin RL, Kasper FK, Mikos AG. Enhanced chondrogenesis in co-cultures with articular chondrocytes and mesenchymal stem cells. Biomaterials. 2012; 33:6362-6369. [PubMed: 22695067]

29. Billiet T, Vandenhaute M, Schelfhout J, Van Vlierberghe S, Dubruel P. A review of trends and limitations in hydrogel-rapid prototyping for tissue engineering. Biomaterials. 2012; 33:6020 6041. [PubMed: 22681979]

30. Butscher A, Bohner M, Hofmann S, Gauckler L, Muller R. Structural and material approaches to bone tissue engineering in powder-based three-dimensional printing. Acta Biomater. 2011; 7:907920. [PubMed: 20920616]

31. Peltola SM, Melchels FPW, Grijpma DW, Kellomaki M. A review of rapid prototyping techniques for tissue engineering purposes. Ann Med. 2008; 40:268-280. [PubMed: 18428020]

32. Godara P, McFarland CD, Nordon RE. Design of bioreactors for mesenchymal stem cell tissue engineering. J Chem Technol Biotechnol. 2008; 83:408-420.

33. Kretlow JD, Mikos AG. Bones to biomaterials and back again--20 years of taking cues from nature to engineer synthetic polymer scaffolds. J Biomed Mater Res, Part A. 2011; 98A:323-331.

34. Ekenseair AK, Boere KW, Tzouanas SN, Vo TN, Kasper FK, Mikos AG. Synthesis and characterization of thermally and chemically gelling injectable hydrogels for tissue engineering. Biomacromolecules. 2012; 13:1908-1915. [PubMed: 22554407]

35. Ekenseair, AK.; Boere, KW.; Tzouanas, SN.; Vo, TN.; Kasper, FK.; Mikos, AG. Structureproperty evaluation of thermally and chemically gelling injectable hydrogels for tissue engineering. Biomacromolecules. (in press; http://dx.doi.org/10.1021/bm300797m)

36. Kretlow JD, Klouda L, Mikos AG. Injectable matrices and scaffolds for drug delivery in tissue engineering. Adv Drug Delivery Rev. 2007; 59:263-273. 